\title{
Wisconsin's Novel Approach to Creating a Health Outcomes Opioid Surveillance System
}

\author{
Milda Aksamitauskas ${ }^{\star 1}$, Lisa Bullard-Cawthorne², Ousmane Diallo', Crystal Gibson², \\ Justin Martin', Richard Miller', Christine P. Muganda', Aman Tandias ${ }^{1}$ and \\ Anne L. Ziege ${ }^{1}$
}

'Office of Health Informatics, Wisconsin Division of Public Health, Madison, WI, USA; ${ }^{2}$ Bureau of Community Health Promotion, Wisconsin Division of Public Health, Madison, WI, USA

\section{Objective}

Wisconsin is leading the way in novel approaches monitoring health outcomes for opioid-related adverse events. This panel will share innovative public health informatics methods that harness various data sources (e.g., Prescription Drug Monitoring Data (PDMP), death, birth and hospitalization data) for population health surveillance. Discussion will include topics on detection of drug abuse and diversion, identifying potential neonatal abstinence syndrome cases, surveillance of substance-related hospitalizations and overdose deaths, and modeling opioid-related mortality risk factors.

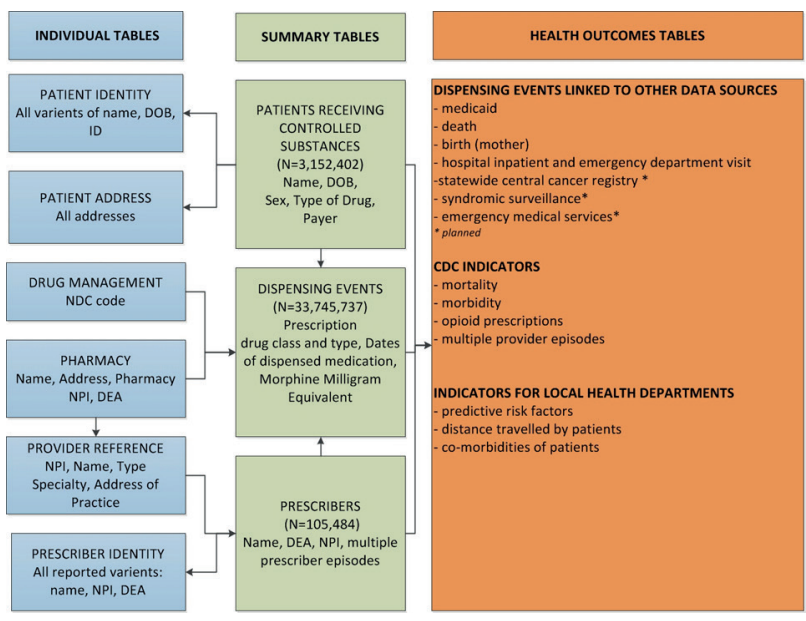

Figure 1. Health Outcomes Opioids Surveillance System Diagram

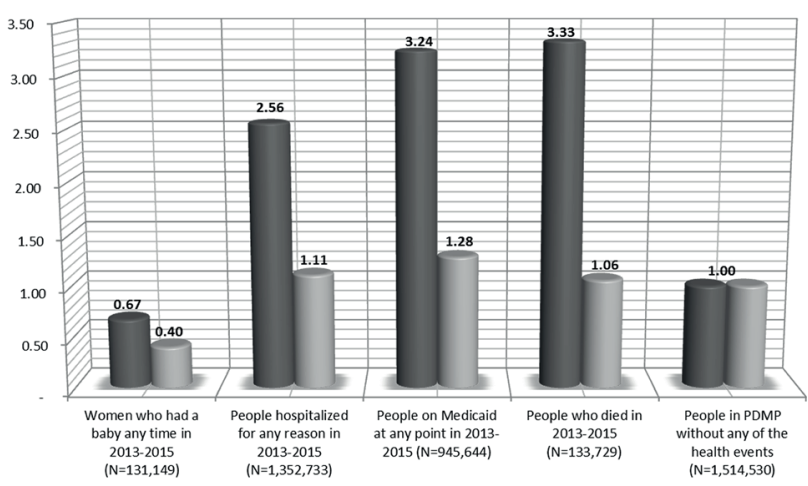

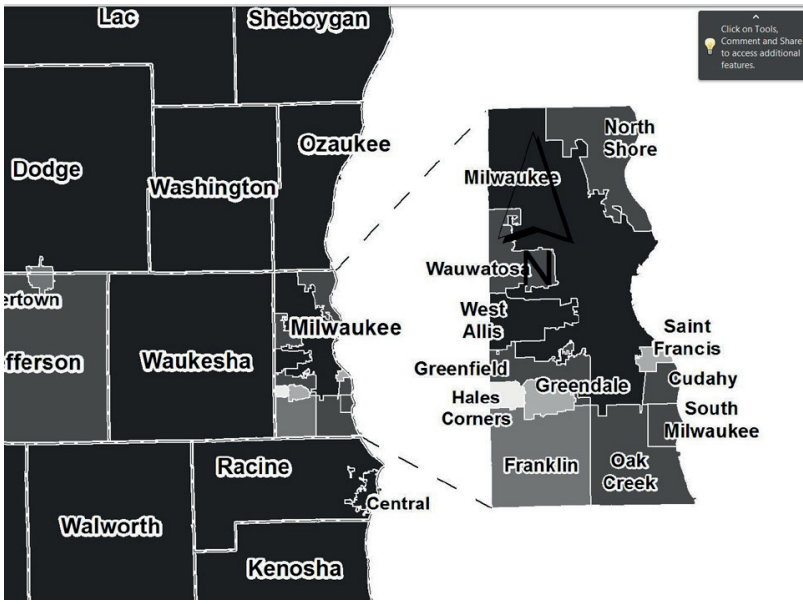

Map 1. Filled Opioids Over 90MME, Southeast Region Local Heaht Departments, Wisconsin, 2015.

\section{Keywords}

Prescription Drug Monitoring Program (PDMP); Substance Abuse; Near real-time surveillance; Automation; Data linking

\section{References}

PDMP Center of Excellence [Internet]. Waltham: Brandeis University, PDMP Center of Excellence; c2010-2013 [cited 2016 August 22]. Available from: <a href="http://www.pdmpexcellence.org/"> http:// www.pdmpexcellence.org $/</ \mathrm{a}>$.

\section{*Milda Aksamitauskas}

E-mail:milda.aksamitauskas@wi.gov 